\title{
Translation initiation mediated by nuclear cap-binding protein complex
}

\author{
Incheol Ryu ${ }^{1,2} \mathcal{E}$ Yoon Ki Kim ${ }^{1,2, *}$ \\ ${ }^{1}$ Creative Research Initiatives Center for Molecular Biology of Translation, Korea University, ${ }^{2}$ School of Life Sciences, Korea University, \\ Seoul 02841, Korea
}

In mammals, cap-dependent translation of mRNAs is initiated by two distinct mechanisms: cap-binding complex (CBC; a heterodimer of CBP80 and 20)-dependent translation (CT) and elF4E-dependent translation (ET). Both translation initiation mechanisms share common features in driving cap- dependent translation; nevertheless, they can be distinguished from each other based on their molecular features and biological roles. CT is largely associated with mRNA surveillance such as nonsense-mediated mRNA decay (NMD), whereas ET is predominantly involved in the bulk of protein synthesis. However, several recent studies have demonstrated that CT and ET have similar roles in protein synthesis and mRNA surveillance. In a subset of mRNAs, CT preferentially drives the cap-dependent translation, as ET does, and ET is responsible for mRNA surveillance, as CT does. In this review, we summarize and compare the molecular features of $\mathrm{CT}$ and ET with a focus on the emerging roles of CT in translation. [BMB Reports 2017; 50(4): 186-193]

\section{INTRODUCTION}

Eukaryotic transcripts synthesized by RNA polymerase II are sequentially and coordinately processed into mature messenger RNAs (mRNAs) through various nuclear events such as transcription, 5'-end capping, splicing, and 3'-end processing/ polyadenylation (1). Early in transcription, the $5^{\prime}$-end of the primary transcript is covalently modified by the addition of a 7-methylguanosine cap, which co-transcriptionally occurs via nuclear capping enzyme $(2,3)$. The $5^{\prime}$-cap structure is recognized by the nuclear cap-binding complex (CBC), composed of a heterodimer of cap-binding protein 80 (CBP80) and cap-binding protein 20 (CBP20) [also known as nuclear cap-binding protein 1 (NCBP1) and nuclear cap-binding

${ }^{*}$ Corresponding author. Tel: +82-2-3290-3410; Fax: +82-2-9239923; E-mail: yk-kim@korea.ac.kr

https://doi.org/10.5483/BMBRep.2017.50.4.007

Received 13 January 2017

Keywords: CBC, eIF4E, NMD, Translation protein 2 (NCBP2), respectively]. The CBC-bound pre-mRNA is further processed by a splicing machinery. As a consequence of splicing, a specialized protein complex named the exon junction complex (EJC), which consists of four core components (elF4A3, MAGOH, Y14, and MLN51) and a number of auxiliary factors, is deposited approximately 20-24 nucleotides upstream of each exon-exon junction $(4,5)$. In addition, the 3 '-end of transcript is cleaved and polyadenylated. The 3'-poly $(\mathrm{A})$ tail is recognized by nuclear poly(A)-binding protein 1 (PABPN1; also known as PABP2) (6). Mature mRNAs are exported from the nucleus to the cytoplasm only after the completion of proper mRNA processing in the nucleus, and they contain a $5^{\prime}$-cap bound by the $\mathrm{CBC}$, 3'-poly(A) tail bound by PABPN1, and exon-exon junctions associated with EJCs. The mRNAs either being exported from the nucleus or completely exported via the nuclear pore complex serve as a template for translation in the cytoplasm.

In the cytoplasm, the $5^{\prime}$-cap directs cap-dependent translation via two distinct pathways: CBC-dependent translation $(\mathrm{CT})$ and eukaryotic translation initiation factor $4 \mathrm{E}$ (elF4E)-dependent translation (ET) (7). CT is believed to precede ET because CBC-bound mRNA is a precursor of elF4E-bound mRNA (8). With respect to their functional roles, it is generally considered that $\mathrm{CT}$ is largely involved in mRNA quality control, whereas ET is in charge of the bulk of protein synthesis (7). However, recent studies have made it harder to define the functional boundary between CT and ET. Therefore, in this review, we describe the recent findings on $\mathrm{CT}$ and compare the molecular features of $\mathrm{CT}$ and ET with a focus on the emerging roles of $\mathrm{CT}$ in eukaryotic gene expression.

\section{MOLECULAR FEATURES OF CT: SIMILARITIES AND DIFFERENCES BETWEEN CT AND ET}

Eukaryotic translation initiation occurs through two distinct steps (Fig. 1); the first is the formation of the $48 \mathrm{~S}$ preinitiation complex (PIC) with codon-anticodon base pairing between the initiator tRNA and a start codon in the $\mathrm{P}$ site of a $40 \mathrm{~S}$ ribosome (a small subunit of ribosome), and the second is the joining of a 605 ribosome (a large subunit of ribosome) to the PIC to form an elongation-competent $80 \mathrm{~S}$ ribosome $(9,10)$. To this

ISSN: 1976-670X (electronic edition)

Copyright (C) 2017 by the The Korean Society for Biochemistry and Molecular Biology

c) This is an open-access article distributed under the terms of the Creative Commons Attribution Non-Commercial License (http://creativecommons.org/licenses/by-nc/4.0) which permits unrestricted non-commercial use, distribution, and reproduction in any medium, provided the original work is properly cited. 


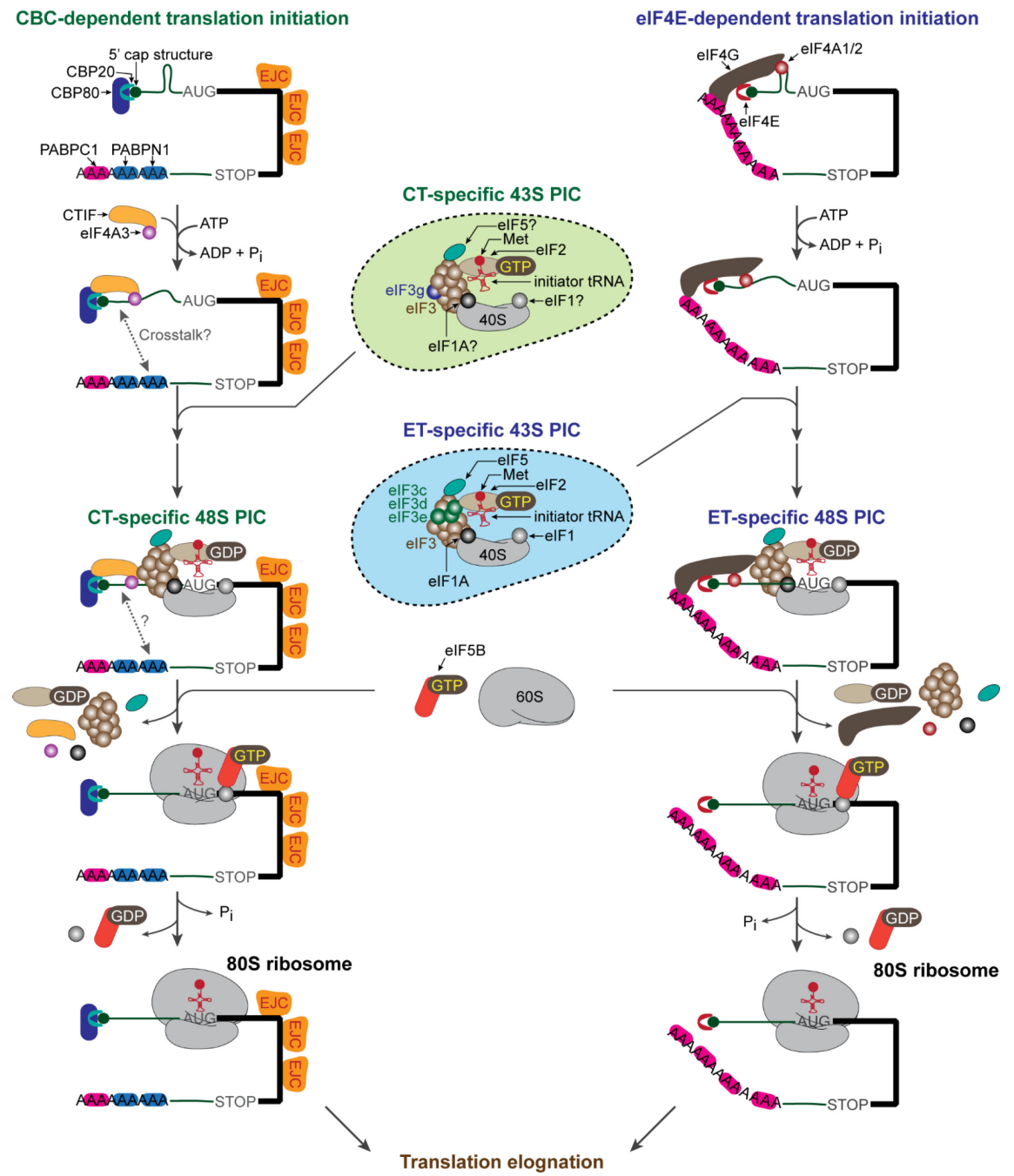

Fig. 1. Mechanistic comparison of CBCdependent translation (CT) and elF4Edependent translation (ET). The details are described in the text. end, the $40 \mathrm{~S}$ ribosome should be physically attached to the cap-binding protein bound to the $5^{\prime}$-cap structure for efficient ribosome scanning through the $5^{\prime}$ untranslated region ( $5^{\prime}$ UTR) to locate the start codon in the proper context. The physical association is mediated by a scaffold protein, which directly binds to the cap-binding protein and elF3 complex (11). Notably, the elF3 complex physically associates with the $40 \mathrm{~S}$ ribosome and various translation initiation factors such as (i) elF1 and elF1A, which confer the fidelity of start codon selection $(12,13)$, (ii) the ternary complex consisting of the elF2 complex (composed of elF $2 \alpha$, elF2 $\beta$, and elF $2 \gamma$ ), GTP, and methionine-charged initiator tRNAi (14), and (iii) elF5, which stimulates the GTPase activity of elF $2 \gamma$ and consequently leads to the conversion of GTP-bound elF2 to GDP-bound elF2 $(9,10)$. The resulting multi-factor complex is called the 43S PIC (or the scanning complex) (9).

For $\mathrm{ET}$, the $40 \mathrm{~S}$ ribosome is attached to the 5'-cap structure via elF4G, which directly binds to elF4E $(9,10)$ and the elF3 complex $(15,16)$. In the case of $C T$, a majority of mRNA-bound $\mathrm{CBC}$ recruits the $40 \mathrm{~S}$ ribosome through physical interactions of a CT-specific factor, CBC-dependent translation initiation factor (CTIF) with CBP80 (17) and the elF3 complex (18). However, an ET-specific factor, elF4G also has an ability to bridge the $\mathrm{CBC}$ and the elF3 complex, although there are some controversial reports (17-21). Intriguingly, elF4G and CTIF serve as a binding platform for the elF3 complex because they share an evolutionarily conserved domain called the middle domain of eukaryotic translation initiation factor 4G (MIF4G domain) with approximately $46 \%$ similarity $(17,22$, 23). However, they directly bind to different subunits of the elF3 complex to recruit the $40 \mathrm{~S}$ ribosome to mRNA (elF3c, elF3d, and elF3e for elF4G and elF3g for CTIF). Initial study of in vitro reconstitution experiments using purified elF3 complex revealed that elF3g is dispensable in elF3 complex formation 
(24). However, a recent mass spectrometric analysis showed that elF3g is located in close proximity to elF3j (25), which is positioned at the decoding center of the $40 \mathrm{~S}$ ribosome (26). In addition, a recent cryoelectron microscopic analysis of the mammalian $48 \mathrm{~S}$ PIC revealed that elF3g is relocated from the peripheral region of the $40 \mathrm{~S}$ ribosome to the $\mathrm{P}$ site at its intersubunit face to promote efficient subunit joining (27). Therefore, elF3g is thought to serve as a platform for the CT complex to easily access the start codon and consequently to assemble an elongation-competent $80 \mathrm{~S}$ ribosome.

After attachment of the $40 \mathrm{~S}$ ribosome to the cap structure, a scanning complex scans for the start codon in the $5^{\prime}$ to $3^{\prime}$ direction along the $5^{\prime}$ UTR. Efficient ribosome scanning requires an ATP-dependent DEAD-box RNA helicase for unwinding RNA secondary or tertiary structures in the $5^{\prime}$ UTR (28). Interestingly, CT and ET exhibit different factor requirements for unwinding the secondary or tertiary structures. For $\mathrm{ET}$, elF4A1 or elF4A2, which directly interacts with elF4G, facilitates efficient unwinding (29-31). In contrast, the CT complex engages elF4A3 through its interaction with CTIF (32). Accordingly, the downregulation of elF4A3 but not elF4A1 and elF4A2 reduces the translational efficiency of CBP80-bound mRNAs harboring moderate secondary structures and blocks CT-associated mRNA quality control (32).

It should be noted that elF4A itself has weak helicase activity $(33,34)$ and thus requires a cofactor to efficiently unwind RNA secondary or tertiary structures in the $5^{\prime} \cup T R$. For ET, the binding of elF4G to elF4A $1 / 2$ converts elF4A $1 / 2$ from a closed to an open conformation, promoting its helicase activity (31). In addition, the helicase activity of elF4A $1 / 2$ is stimulated by elF4B and elF4H $(28,35)$. However, it is not yet known what cellular factor(s) can modulate the helicase activity of elF4A3 during CT. One plausible candidate is MLN51, a component of the EJC, as MLN51 has been found to enhance the helicase activity of elF4A3 $(36,37)$. As elF4G does $(28,31)$, it is also likely that CTIF could facilitate conformational change of elF4A3 to promote the helicase activity.

After the scanning complex finally reaches the start codon, the $48 \mathrm{~S} \mathrm{PIC} \mathrm{undergoes} \mathrm{drastic} \mathrm{remodeling.} \mathrm{elF5} \mathrm{in} \mathrm{association}$ with the elF3 complex stimulates the GTPase activity of elF2 $\gamma$ of the elF2 complex, converting elF2-GTP to elF2-GDP (14). Then, elF5B (a ribosome-dependent GTPase) triggers the dissociation of elF1, elF1A, elF2-GDP, elF3, and elF5 from the $40 \mathrm{~S}$ ribosome and facilitates the joining of the $60 \mathrm{~S}$ ribosome (38-40). Subsequently, the GTPase activity of elF5B is stimulated, releasing elF5B from the ribosome. A majority of studies on the mechanism of this step have focused on ET, particularly by adopting in vitro reconstitution approaches. Considering that the overall initiation process of $\mathrm{CT}$ is similar to that of ET, it is possible that CT may follow a comparable route for $48 \mathrm{~S} \mathrm{PIC} \mathrm{assembly} \mathrm{and} \mathrm{subsequent} 60 \mathrm{~S}$ joining using canonical initiation factors as well as CT-specific factors such as CTIF and elF4A3.

In addition to the $5^{\prime}$-cap structure, the poly(A) tail is critical for efficient cap-dependent translation (41). During ET, cytoplasmic poly(A)-binding protein 1 (PABPC1; also known as PABP1) associates with the poly(A) tail of mRNAs and interacts with elF4G via direct binding to the PAM1 motif in the N-terminus of elF4G (42). This interaction enhances the efficiency of ET either by augmenting the cap-binding ability of eIF4E $(43,44)$, which may lead to stable mRNA circularization (45), or by directly or indirectly facilitating the recruitment of the 605 ribosome to the $48 \mathrm{~S}$ PIC (46). In addition, PABPC1 binds to eukaryotic polypeptide chain release factor 3 (eRF3), one of translation release factors that promotes translation termination $(47,48)$. In contrast, there is no known CT-specific poly(A)-binding protein, and whether the poly(A) tail of CBC-bound mRNAs is involved in CT has not been confirmed. Notably, there is no characterized binding motif or domain within CBP80 and CTIF for binding to poly(A)-binding proteins (either PABPN1 or PABPC1). However, considering that PABPN1 forms a complex with the $\mathrm{CBC}$ but not with elF4E (20) and that it is detected in actively translating polysomes (49), the possibility that PABPN1 may participate in CT cannot be completely ruled out.

\section{CT VS. ET IN NONSENSE-MEDIATED mRNA DECAY}

During mRNA processing in eukaryotic cells, premature termination codons (PTCs) can arise on mRNAs as a consequence of mutations in somatic cells, inaccurate transcription or splicing, or alternative splicing that leads to intron retention or inclusion of a PTC-containing exon (50). These aberrant mRNAs would express truncated polypeptides, the accumulation of which is potentially deleterious to the cells. Fortunately, eukaryotic cells have evolved several mRNA quality control pathways, which are typified by nonsensemediated mRNA decay (NMD). The aberrant mRNAs harboring PTCs would be selectively recognized and rapidly degraded by the NMD pathway before truncated polypeptides are accumulated within the cells $(7,51-53)$.

Efficient NMD requires at least a single round of translation to recognize the PTCs on mRNAs. NMD has long been considered to occur during CT because (i) CBC-bound mRNAs are precursors of elF4E-bound mRNAs, (ii) the $\mathrm{CBC}$ can drive cap-dependent translation, and (iii) the majority of NMD occurs on CBC-bound mRNAs $(7,8,20,49,54,55)$. Therefore, the traditional model of CT-coupled NMD can be described as follows: newly synthesized CBC-bound and EJC-deposited mRNAs are subject to the first round of translation during or after their export from the nucleus to the cytoplasm. The first round of translation would be predominantly mediated by the CBC rather than elF4E because newly synthesized mRNAs have a 5'-end cap bound by the CBC. During the first round of CBC-mediated translation, an elongating $80 S$ ribosome removes EJCs deposited 20-24 nucleotides upstream of exon-exon junctions after splicing. When the elongating $80 \mathrm{~S}$ ribosome reaches a termination codon, eRF1 and eRF3 are recruited to 
the terminating ribosome along with UPF1 (a key NMD factor) and SMG1 kinase, forming the SMG1-UPF1-eRF1/3 (SURF) complex. The stability of the SURF complex is dependent on the presence or absence of EJCs downstream of the termination codon. The SURF complex would be unstable if there is no EJC downstream of the termination codon; consequently, the termination codon would be recognized as "normal", and the mRNA would be stable. On the other hand, if EJC is present downstream of the termination codon, it interacts with the SURF complex and induces complex remodeling; consequently, the termination codon would be recognized as a "PTC", and the mRNA would be rapidly degraded via exoribonucleolytic or endoribonucleolytic cleavage.

Recently, two separate studies claimed that NMD can occur on elF4E-bound mRNAs as well as CBC-bound mRNAs (56, 57). To verify their hypothesis, they examined the efficiency of NMD under conditions where ET is compromised. The studies found that treatment of cells with $4 \mathrm{EGl}-1$, a specific translational inhibitor, which disrupts the interaction between elF4E and elF4G (58), and overexpression of elF4E-BP1, which competes with elF4G for binding to elF4E (59), suppressed the NMD of PTC-containing mRNAs (e.g., $\beta$-globin and GPx1). Furthermore, the half-life of PTC-containing mRNAs (e.g., $\beta$-globin, immunoglobulin $\mu$, and TCR $\beta$ ) was also decreased in elF4E-bound messenger ribonucleoproteins (mRNPs) as well as in CBP80-bound mRNPs. In addition, elF4E was found to be associated with UPF1 in an RNA-dependent manner. Based on these observations, the authors proposed that both $\mathrm{CBC}$-bound and elF4E-bound mRNAs are subject to NMD.

Although the data are compelling, several key issues should be carefully considered. First, considering that CBC-bound mRNA is a precursor of elF4E-bound mRNA, it is likely that a majority of the first round of translation may be predominantly mediated by the $\mathrm{CBC}$ rather than eIF4E. Therefore, it should be clearly determined whether the observed reduction in the level and half-life of elF4E-bound NMD substrates simply reflects the reduction in the level and half-life of CBC-bound NMD substrates. Second, although 4EGl-1 was originally reported as a specific compound that inhibits ET (58), several subsequent studies have reported additional $4 \mathrm{EGI}-1$ targets besides the interaction between elF4E and elF4G $(60,61)$. Notably, it has been reported that treatment of cells with $4 \mathrm{EGI}-1$ in relatively low concentrations strongly inhibited translation without significant changes in elF4F levels; on the other hand, 4EGl-1 treatment increased the association of the 5'-cap with ribosomal complexes containing the phosphorylated (inactive) form of elF2 (60). This effect would inhibit the efficiency of both CT and ET. Third, CBC-bound mRNPs but not elF4Econtaining mRNPs contain detectable amounts of EJCs, which are critical for stimulating the NMD of PTC-containing mRNAs $(8,17,20,32,49,62)$. Therefore, as mentioned earlier, the rapid degradation of NMD substrates in elF4E-containing mRNPs would reflect the rapid degradation of NMD substrates in $\mathrm{CBC}$-containing mRNPs. However, another equally plausible explanation is that CBC-bound NMD substrates may be predominantly subject to EJC-dependent NMD, whereas elF4Ebound NMD substrates may be subject to EJC-independent NMD. Fourth, the replacement of the CBC by elF4E occurs in a translation-independent manner (55). Therefore, even before the complete termination of $\mathrm{CT}, \mathrm{CBC}$ would be replaced by elF4E, suggesting the possibility of a transient interaction between elF4E and UPF1.

Recently, two independent studies revealed that mammalian target of rapamycin complex 1 (mTORC1), which specifically controls ET efficiency by phosphorylating elF4E-BP (63), can modulate the efficiency of NMD $(64,65)$. One study demonstrated that insulin treatment increased the interaction between UPF1 and elF4E-bound PTC-containing mRNAs and augmented elF4E-associated NMD, which was blocked by treatment with rapamycin (a selective inhibitor of mTORC1) (65). On the other hand, another study reported that rapamycin treatment promoted the NMD of a subset of mRNAs, probably by blocking the replacement of CBC by elF4E (64). Therefore, it would be interesting to determine whether there are CT-specific or ET-specific NMD substrates depending on cellular conditions.

\section{REPLICATION-DEPENDENT HISTONE mRNAs ARE LARGELY TRANSLATED VIA CT}

Histone genes are essential as structural and functional units for packaging genomic DNA into chromatin to sustain genomic integrity and for regulating transcriptional activity, respectively $(66,67)$. In particular, the expression of replicationdependent histone $(\mathrm{RDH})$ genes is tightly controlled during the cell cycle. Upon entry into the $\mathrm{S}$ phase, the levels of RDH mRNAs increase by approximately 35 -fold at the transcriptional level (68). Newly synthesized RDH transcripts are processed into mature RDH mRNAs with the aid of (i) U7 small nuclear ribonucleoprotein (U7 snRNP), which interacts with histone downstream element (HDE), (ii) stem-loop binding protein (SLBP), which directly binds to the histone stem-loop (HSL) located in the $3^{\prime}$ UTR, and (iii) a $3^{\prime}$-end cleavage complex containing cleavage and polyadenylation specificity factor subunit 73 (CPSF73), CPSF100, and symplekin $(69,70)$. The site between the HSL (recognized by SLBP) and the HDE (base-paired with U7 snRNA) is cleaved by CPSF73 and further trimmed by ERI1, a 3'-to-5' exonuclease. The resulting RDH mRNAs, which have a HSL instead of a poly(A) tail, are exported from the nucleus to the cytoplasm for translation. On the other hand, at the end of $\mathrm{S}$ phase or under genotoxic stresses, actively translating $\mathrm{RDH}$ mRNAs are rapidly degraded via hyperphosphorylation of UPF1, which recruits various mRNA degradation factors to $\mathrm{RDH}$ mRNAs (70-72).

$\mathrm{RDH}$ mRNAs are unique in their structure because they lack a poly(A) tail but instead have a conserved HSL at their 3'UTR. In the case of canonical mRNAs, the interaction between 
PABPC1 and elF4G triggers mRNA circularization for efficient translation. Similarly, the circularization of RDH mRNAs has been proposed to be mediated by an indirect interaction between SLBP and elF4G via SLBP-interacting protein 1 (SLIP1), suggesting a possible role of ET in the translation of RDH mRNAs (73). However, this view was recently challenged by two reports demonstrating that the degradation of $\mathrm{RDH}$ mRNAs largely occurs on CBC-bound RDH mRNAs $(32,74)$. Considering that (i) $\mathrm{RDH}$ mRNA degradation requires translation $(75,76)$ and (ii) SLIP1-mediated RDH mRNA circularization increases the ET of RDH mRNAs (73), the elF4Ebound RDH mRNPs are expected to be subject to rapid decay. In contrast, the authors found that a majority of RDH mRNA degradation occurs on CBC-bound RDH mRNAs depending on the direct association between CTIF and SLBP (74). Downregulation of a CT-specific factor, either CTIF or elF4A3, was found to increase the abundance of RDH mRNAs. Furthermore, overexpression of elF4E-BP1 or elF4E-T did not affect the levels of RDH mRNAs. These observations support that the majority of RDH mRNAs are translated via CT instead of ET. Although the two studies described above have conflicting results, the findings indicated that at least a subset of mRNAs (e.g. RDH mRNAs) may preferentially use CT instead of ET for protein synthesis and mRNA degradation.

\section{DIFFERENTIAL REGULATION OF CT AND ET UNDER STRESS CONDITIONS}

Eukaryotic cap-dependent translation is regulated at various steps under certain conditions such as oxidative stress, hypoxia, viral infection, apoptosis, nutrient starvation, differentiation, and development $(77,78)$. Under stress conditions, two main factors involved in translation initiation are posttranslationally regulated: phosphorylation of elF2 $\alpha$ (Fig. 2) and elF4E-BP (Fig. 3). GTP-bound elF2 associates with the initiator

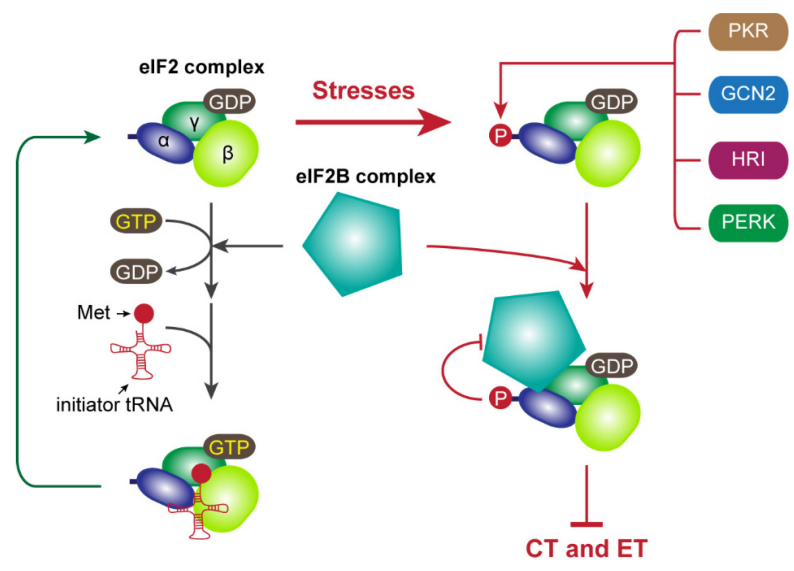

Fig. 2. Translational control mediated by elF $2 \alpha$ phosphorylation under stress conditions. The details are described in the text.
tRNA (14). After establishment of the $48 \mathrm{~S}$ PIC onto the start codon, elF5 stimulates the conversion of elF2-GTP to elF2-GDP, which is released from the ribosome after the joining of the 605 ribosome (38-40). The released elF2-GDP binds to elF2B, which is an elF2-specific guanosine exchange factor (GEF), and is converted to elF2-GTP for recycling (14). However, under stress conditions, several elF2-specific kinases are activated and phosphorylate Ser51 in elF $2 \alpha$, which include PERK (ER stress), PKR (double-stranded RNA upon viral infection), HRI (heme deficiency), and GCN2 (amino acid starvation) (14, 77-79). The phosphorylated elF2 complex sequesters elF2B, leading to a decrease in the amount of available eIF2-GTP and shutdown of translation. Therefore, both $\mathrm{CT}$ and ET can be blocked by elF2 $\alpha$ phosphorylation as both types of translation require a functionally active elF2 complex (Fig. 2).

In addition to elF $2 \alpha$, the phosphorylation status of elF4E-BP is changed in response to intrinsic or extrinsic stresses. elF4E-BP competes with elF4G for binding to elF4E (59). Under normal or actively growing conditions, active mTORC1 phosphorylates elF4E-BP, leading to the decreased binding of elF4E-BP to elF4E and consequently resulting in an increase in ET efficiency $(59,63)$. However, under stress conditions, eIF4E-BP becomes hypophosphorylated and strongly binds to elF4E, resulting in the inhibition of ET. Therefore, elF4E-BP is an ET-specific translation regulator, and $\mathrm{CT}$ is insensitive to elF4E-BP activity (Fig. 3).

In comparison with ET, CT is relatively insensitive to certain environmental stresses, and this can be demonstrated by translational regulation during hypoxia, a condition in which cells or tissues have low oxygen levels. Global translation is regulated during hypoxic stresses at two independent stages: (i) elF2 $\alpha$ phosphorylation at the early stage (acute/moderate hypoxia) and (ii) elF4E-BP hypophosphorylation and elF4E sequestration into the nucleus or the cytoplasmic processing bodies at the late stage (prolonged hypoxia) (80-83). The former induces the global shutdown of protein synthesis by

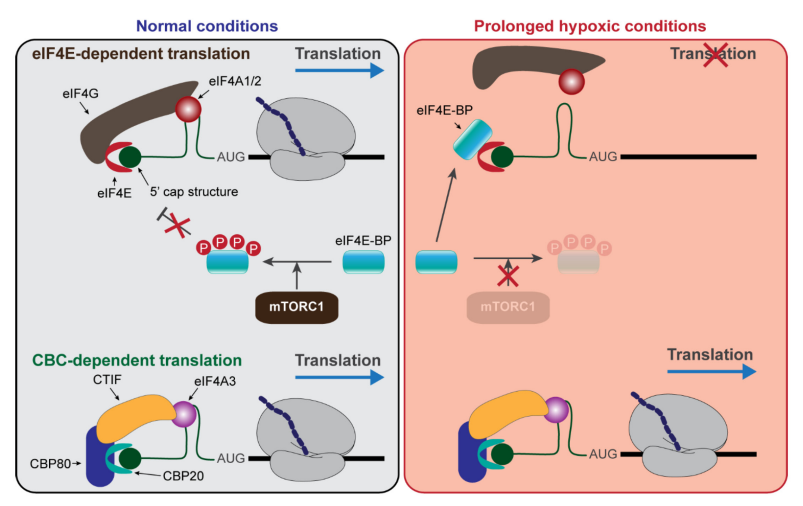

Fig. 3. Translational control under prolonged hypoxic conditions. The details are described in the text. 
targeting both $\mathrm{CT}$ and $\mathrm{ET}$, whereas the latter blocks ET but not CT. Accordingly, acute hypoxia inhibits NMD (84), whereas prolonged hypoxia does not affect NMD even though ET is markedly compromised (85). The relative resistance of CT to environmental stresses is further demonstrated by translational regulation under serum starved conditions, in which mTORC1 is inactivated and the amount of hypophosphorylated elF4E-BP is elevated. Under these conditions, ET efficiency is drastically reduced. However, CT-coupled NMD remains efficient (86). Taken together, CT could support the translation of a subset of mRNAs under stress conditions when ET is compromised.

\section{CONCLUSION REMARKS}

CT and ET have long been considered to be largely involved in mRNA quality control and the bulk of protein synthesis, respectively. However, recent studies have reassessed their roles in translation initiation, revealing that both CT and ET are functionally interchangeable. Although definitive conclusions are difficult given the contradictory data, the following general conclusions can be made:

(i) NMD occurs during $\mathrm{CT}$ or $\mathrm{ET}$; however, $\mathrm{NMD}$ is predominantly coupled to CT.

(ii) CT instead of ET is preferred in the protein synthesis of a subset of mRNAs. In other words, CT can drive multiple rounds of translation of a subset of mRNAs, similar to ET (17, 87-89).

(iii) In comparison with ET, CT is relatively resistant to intrinsic or extrinsic stresses.

In this context, future studies should elucidate the molecular features of $\mathrm{CT}$, identify mRNAs that are specific to CT or ET, and evaluate CT- or ET-specific NMD.

\section{ACKNOWLEDGEMENTS}

This work was supported by the National Research Foundation (NRF) of Korea grant funded by the Korean government (Ministry of Science, ICT, and Future Planning; NRF-2015R1A3A203 3665) and by a Korea University grant. I.R. was in part supported by NRF (NRF-2016R1D1A1B03933894).

\section{CONFLICTS OF INTEREST}

The authors have no conflicting financial interests.

\section{REFERENCES}

1. Singh G, Pratt G, Yeo GW and Moore MJ (2015) The Clothes Make the mRNA: Past and Present Trends in mRNP Fashion. Ann Rev Biochem 84, 325-354

2. Shatkin AJ and Manley JL (2000) The ends of the affair: capping and polyadenylation. Nat Struct Biol 7, 838-842

3. Cowling VH (2010) Regulation of mRNA cap methylation. Biochem J 425, 295-302

4. Le Hir H, Sauliere J and Wang Z (2016) The exon junction complex as a node of post-transcriptional networks. Nat Rev Mol Cell Biol 17, 41-54

5. Woodward LA, Mabin JW, Gangras P and Singh G (2016) The exon junction complex: a lifelong guardian of mRNA fate. Wiley Interdiscip Rev RNA e1411

6. Banerjee A, Apponi LH, Pavlath GK and Corbett $\mathrm{AH}$ (2013) PABPN1: molecular function and muscle disease. FEBS J 280, 4230-4250

7. Maquat LE, Tarn WY and Isken O (2010) The pioneer round of translation: features and functions. Cell 142, 368-374

8. Lejeune F, Ishigaki Y, Li X and Maquat LE (2002) The exon junction complex is detected on CBP80-bound but not elF4E-bound mRNA in mammalian cells: dynamics of mRNP remodeling. EMBO J 21, 3536-3545

9. Jackson RJ, Hellen CU and Pestova TV (2010) The mechanism of eukaryotic translation initiation and principles of its regulation. Nat Rev Mol Cell Biol 11, 113-127

10. Hinnebusch AG (2014) The scanning mechanism of eukaryotic translation initiation. Ann Rev Biochem 83, 779-812

11. Hinnebusch AG (2006) elF3: a versatile scaffold for translation initiation complexes. Trends Biochem Sci 31, 553-562

12. Majumdar R, Bandyopadhyay A and Maitra U (2003) Mammalian translation initiation factor elF1 functions with elF1A and elF3 in the formation of a stable $40 \mathrm{~S}$ preinitiation complex. J Biol Chem 278, 6580-6587

13. Pestova TV, Borukhov SI and Hellen CU (1998) Eukaryotic ribosomes require initiation factors 1 and $1 \mathrm{~A}$ to locate initiation codons. Nature 394, 854-859

14. Proud CG (2005) elF2 and the control of cell physiology. Semin Cell Dev Biol 16, 3-12

15. Villa N, Do A, Hershey JW and Fraser CS (2013) Human eukaryotic initiation factor $4 \mathrm{G}$ (elF4G) protein binds to elF3c, -d, and -e to promote mRNA recruitment to the ribosome. J Biol Chem 288, 32932-32940

16. LeFebvre AK, Korneeva NL, Trutschl M et al (2006) Translation initiation factor elF4G-1 binds to elF3 through the elF3e subunit. J Biol Chem 281, 22917-22932

17. Kim KM, Cho H, Choi K et al (2009) A new MIF4G domain-containing protein, CTIF, directs nuclear capbinding protein CBP80/20-dependent translation. Genes Dev 23, 2033-2045

18. Choe J, Oh N, Park S et al (2012) Translation initiation on mRNAs bound by nuclear cap-binding protein complex CBP80/20 requires interaction between CBP80/20-dependent translation initiation factor and eukaryotic translation initiation factor 3g. J Biol Chem 287, 18500-18509

19. Lejeune F, Ranganathan AC and Maquat LE (2004) elF4G is required for the pioneer round of translation in mammalian cells. Nat Struct Mol Biol 11, 992-1000

20. Ishigaki Y, Li X, Serin G and Maquat LE (2001) Evidence for a pioneer round of mRNA translation: mRNAs subject to nonsense-mediated decay in mammalian cells are bound by CBP80 and CBP20. Cell 106, 607-617

21. McKendrick L, Thompson E, Ferreira J, Morley SJ and Lewis JD (2001) Interaction of eukaryotic translation initiation factor $4 \mathrm{G}$ with the nuclear cap-binding complex provides a link between nuclear and cytoplasmic func- 
tions of the $\mathrm{m}(7)$ guanosine cap. Mol Cell Biol 21, 3632-3641

22. von Moeller $H$, Lerner R, Ricciardi A, Basquin C, Marzluff WF and Conti E (2013) Structural and biochemical studies of SLIP1-SLBP identify DBP5 and elF3g as SLIP1-binding proteins. Nucleic Acids Res 41, 7960-7971

23. Marintchev A and Wagner G (2004) Translation initiation: structures, mechanisms and evolution. Q Rev Biophys 37, 197-284

24. Masutani $M$, Sonenberg N, Yokoyama S and Imataka H (2007) Reconstitution reveals the functional core of mammalian elF3. EMBO J 26, 3373-3383

25. Zhou M, Sandercock AM, Fraser CS et al (2008) Mass spectrometry reveals modularity and a complete subunit interaction map of the eukaryotic translation factor elF3. Proc Natl Acad Sci U S A 105, 18139-18144

26. Fraser CS, Berry KE, Hershey JW and Doudna JA (2007) elF3j is located in the decoding center of the human $40 \mathrm{~S}$ ribosomal subunit. Mol Cell 26, 811-819

27. Simonetti A, Brito Querido J, Myasnikov AG et al (2016) elF3 Peripheral Subunits Rearrangement after mRNA Binding and Start-Codon Recognition. Mol Cell 63, 206-217

28. Parsyan A, Svitkin Y, Shahbazian D et al (2011) mRNA helicases: the tacticians of translational control. Nat Rev Mol Cell Biol 12, 235-245

29. Pestova TV and Kolupaeva VG (2002) The roles of individual eukaryotic translation initiation factors in ribosomal scanning and initiation codon selection. Genes Dev 16, 2906-2922

30. Marintchev A, Edmonds KA, Marintcheva B et al (2009) Topology and regulation of the human elF4A/4G/4H helicase complex in translation initiation. Cell 136, 447460

31. Oberer M, Marintchev A and Wagner G (2005) Structural basis for the enhancement of elF4A helicase activity by elF4G. Genes Dev 19, 2212-2223

32. Choe J, Ryu I, Park OH et al (2014) elF4AIII enhances translation of nuclear cap-binding complex-bound mRNAs by promoting disruption of secondary structures in 5'UTR. Proc Natl Acad Sci U S A 111, E4577-4586

33. Rogers GW Jr, Richter NJ and Merrick WC (1999) Biochemical and kinetic characterization of the RNA helicase activity of eukaryotic initiation factor 4A. J Biol Chem 274, 12236-12244

34. Li Q, Imataka H, Morino S et al (1999) Eukaryotic translation initiation factor 4AIII (elF4AIII) is functionally distinct from elF4AI and elF4All. Mol Cell Biol 19, 7336-7346

35. Lu WT, Wilczynska A, Smith E and Bushell M (2014) The diverse roles of the elF4A family: you are the company you keep. Biochem Soc T 42, 166-172

36. Ballut L, Marchadier B, Baguet A, Tomasetto C, Seraphin $\mathrm{B}$ and Le Hir H (2005) The exon junction core complex is locked onto RNA by inhibition of elF4AIII ATPase activity. Nat Struct Mol Biol 12, 861-869

37. Noble CG and Song H (2007) MLN51 stimulates the RNA-helicase activity of elF4AIII. PLoS One 2, e303

38. Unbehaun A, Borukhov SI, Hellen CU and Pestova TV (2004) Release of initiation factors from $48 \mathrm{~S}$ complexes during ribosomal subunit joining and the link between establishment of codon-anticodon base-pairing and hydrolysis of elF2-bound GTP. Genes Dev 18, 3078-3093

39. Lee JH, Pestova TV, Shin BS, Cao C, Choi SK and Dever TE (2002) Initiation factor elF5B catalyzes second GTPdependent step in eukaryotic translation initiation. Proc Natl Acad Sci U S A 99, 16689-16694

40. Pestova TV, Lomakin IB, Lee JH, Choi SK, Dever TE and Hellen CU (2000) The joining of ribosomal subunits in eukaryotes requires elF5B. Nature 403, 332-335

41. Weill L, Belloc E, Bava FA and Mendez R (2012) Translational control by changes in poly(A) tail length: recycling mRNAs. Nat Struct Mol Biol 19, 577-585

42. Imataka H, Gradi A and Sonenberg N (1998) A newly identified $\mathrm{N}$-terminal amino acid sequence of human elF4G binds poly(A)-binding protein and functions in poly(A)-dependent translation. EMBO J 17, 7480-7489

43. von Der Haar T, Ball PD and McCarthy JE (2000) Stabilization of eukaryotic initiation factor $4 \mathrm{E}$ binding to the mRNA 5'-Cap by domains of elF4G. J Biol Chem 275, 30551-30555

44. Borman AM, Michel YM and Kean KM (2000) Biochemical characterisation of cap-poly(A) synergy in rabbit reticulocyte lysates: the elF4G-PABP interaction increases the functional affinity of elF4E for the capped mRNA 5'-end. Nucleic Acids Res 28, 4068-4075

45. Wells SE, Hillner PE, Vale RD and Sachs AB (1998) Circularization of mRNA by eukaryotic translation initiation factors. Mol Cell 2, 135-140

46. Kahvejian A, Svitkin YV, Sukarieh R, M'Boutchou MN and Sonenberg N (2005) Mammalian poly(A)-binding protein is a eukaryotic translation initiation factor, which acts via multiple mechanisms. Genes Dev 19, 104-113

47. Hoshino S, Imai M, Kobayashi T, Uchida N and Katada T (1999) The eukaryotic polypeptide chain releasing factor (eRF3/GSPT) carrying the translation termination signal to the 3'-Poly(A) tail of mRNA. Direct association of erf3/GSPT with polyadenylate-binding protein. J Biol Chem 274, 16677-16680

48. Jackson RJ, Hellen CU and Pestova TV (2012) Termination and post-termination events in eukaryotic translation. Adv Protein Chem Str 86, 45-93

49. Chiu SY, Lejeune F, Ranganathan AC and Maquat LE (2004) The pioneer translation initiation complex is functionally distinct from but structurally overlaps with the steady-state translation initiation complex. Genes Dev $18,745-754$

50. He F and Jacobson A (2015) Nonsense-Mediated mRNA Decay: Degradation of Defective Transcripts Is Only Part of the Story. Ann Rev Gene 49, 339-366

51. Fatscher T, Boehm V and Gehring NH (2015) Mechanism, factors, and physiological role of nonsense-mediated mRNA decay. Cell Mol Life Sci 72, 4523-4544

52. Karousis ED, Nasif S and Muhlemann O (2016) Nonsensemediated mRNA decay: novel mechanistic insights and biological impact. Wiley Interdiscip Rev RNA 7, 661-682

53. Hwang J and Kim YK (2013) When a ribosome encounters a premature termination codon. BMB Rep 46, 9-16

54. Kurosaki T and Maquat LE (2016) Nonsense-mediated mRNA decay in humans at a glance. J Cell Sci 129, 461-467 
55. Sato $\mathrm{H}$ and Maquat LE (2009) Remodeling of the pioneer translation initiation complex involves translation and the karyopherin importin beta. Genes Dev 23, 2537-2550

56. Durand S and Lykke-Andersen J (2013) Nonsensemediated mRNA decay occurs during elF4F-dependent translation in human cells. Nat Struct Mol Biol 20, 702-709

57. Rufener SC and Muhlemann O (2013) elF4E-bound mRNPs are substrates for nonsense-mediated mRNA decay in mammalian cells. Nat Struct Mol Biol 20, 710-717

58. Moerke NJ, Aktas H, Chen $\mathrm{H}$ et al (2007) Small-molecule inhibition of the interaction between the translation initiation factors elF4E and elF4G. Cell 128, 257-267

59. Qin X, Jiang B and Zhang Y (2016) 4E-BP1, a multifactor regulated multifunctional protein. Cell cycle 15, 781-786

60. McMahon R, Zaborowska I and Walsh D (2011) Noncytotoxic inhibition of viral infection through elF4F-independent suppression of translation by 4EGi-1. J Virol 85, 853-864

61. Mokas S, Mills JR, Garreau C et al (2009) Uncoupling stress granule assembly and translation initiation inhibition. Mol Biol Cell 20, 2673-2683

62. Kashima I, Yamashita A, Izumi $\mathrm{N}$ et al (2006) Binding of a novel SMG-1-Upf1-eRF1-eRF3 complex (SURF) to the exon junction complex triggers Upf1 phosphorylation and nonsense-mediated mRNA decay. Genes Dev 20, 355-367

63. Ma XM and Blenis J (2009) Molecular mechanisms of mTOR-mediated translational control. Nat Rev Mol Cell Biol 10, 307-318

64. Martinez-Nunez RT, Wallace A, Coyne D et al (2016) Modulation of nonsense mediated decay by rapamycin. Nucleic Acids Res [Epub ahead of print]

65. Park J, Ahn S, Jayabalan AK, Ohn T, Koh HC and Hwang J (2016) Insulin Signaling Augments elF4E-Dependent Nonsense-Mediated mRNA Decay in Mammalian Cells. Biochim Biophys Acta 1859, 896-905

66. Rattray AM and Muller B (2012) The control of histone gene expression. Biochem Soc T 40, 880-885

67. Marzluff WF, Wagner EJ and Duronio RJ (2008) Metabolism and regulation of canonical histone mRNAs: life without a poly(A) tail. Nat Rev Genet 9, 843-854

68. Harris ME, Bohni R, Schneiderman MH, Ramamurthy L, Schumperli D and Marzluff WF (1991) Regulation of histone mRNA in the unperturbed cell cycle: evidence suggesting control at two posttranscriptional steps. Mol Cell Biol 11, 2416-2424

69. Romeo V and Schumperli D (2016) Cycling in the nucleus: regulation of RNA 3' processing and nuclear organization of replication-dependent histone genes. Curr Opin Cell Biol 40, 23-31

70. Hoefig KP and Heissmeyer V (2014) Degradation of oligouridylated histone mRNAs: see UUUUU and goodbye. Wiley Interdiscip Rev RNA 5, 577-589

71. Kaygun $\mathrm{H}$ and Marzluff WF (2005) Regulated degradation of replication-dependent histone mRNAs requires both ATR and Upf1. Nat Struct Mol Biol 12, 794-800

72. Choe J, Ahn SH and Kim YK (2014) The mRNP remodeling mediated by UPF1 promotes rapid degradation of replication-dependent histone mRNA. Nucleic Acids Res 42, 9334-9349

73. Cakmakci NG, Lerner RS, Wagner EJ, Zheng $L$ and
Marzluff WF (2008) SLIP1, a factor required for activation of histone mRNA translation by the stem-loop binding protein. Mol Cell Biol 28, 1182-1194

74. Choe J, Kim KM, Park S et al (2013) Rapid degradation of replication-dependent histone mRNAs largely occurs on mRNAs bound by nuclear cap-binding proteins 80 and 20. Nucleic Acids Res 41, 1307-1318

75. Stimac E, Groppi VE Jr and Coffino P (1984) Inhibition of protein synthesis stabilizes histone mRNA. Mol Cell Biol 4, 2082-2090

76. Graves RA, Pandey NB, Chodchoy N and Marzluff WF (1987) Translation is required for regulation of histone mRNA degradation. Cell 48, 615-626

77. Holcik M and Sonenberg N (2005) Translational control in stress and apoptosis. Nat Rev Mol Cell Biol 6, 318-327

78. Gebauer F and Hentze MW (2004) Molecular mechanisms of translational control. Nat Rev Mol Cell Biol 5, 827-835

79. Yamasaki S and Anderson P (2008) Reprogramming mRNA translation during stress. Curr Opin Cell Biol 20, 222-226

80. Koritzinsky $M$, Magagnin MG, van den Beucken $T$ et al (2006) Gene expression during acute and prolonged hypoxia is regulated by distinct mechanisms of translational control. EMBO J 25, 1114-1125

81. Koumenis C, Naczki C, Koritzinsky M et al (2002) Regulation of protein synthesis by hypoxia via activation of the endoplasmic reticulum kinase PERK and phosphorylation of the translation initiation factor elF2alpha. Mol Cell Biol 22, 7405-7416

82. Arsham AM, Howell JJ and Simon MC (2003) A novel hypoxia-inducible factor-independent hypoxic response regulating mammalian target of rapamycin and its targets. J Biol Chem 278, 29655-29660

83. Dostie J, Ferraiuolo M, Pause A, Adam SA and Sonenberg $\mathrm{N}$ (2000) A novel shuttling protein, 4E-T, mediates the nuclear import of the mRNA 5' cap-binding protein, elF4E. EMBO J 19, 3142-3156

84. Gardner LB (2008) Hypoxic inhibition of nonsensemediated RNA decay regulates gene expression and the integrated stress response. Mol Cell Biol 28, 3729-3741

85. Oh N, Kim KM, Choe J and Kim YK (2007) Pioneer round of translation mediated by nuclear cap-binding proteins CBP80/20 occurs during prolonged hypoxia. FEBS Lett $581,5158-5164$

86. Oh N, Kim KM, Cho H, Choe J and Kim YK (2007) Pioneer round of translation occurs during serum starvation. Biochem Bioph Res Co 362, 145-151

87. Apcher S, Daskalogianni C, Lejeune F et al (2011) Major source of antigenic peptides for the MHC class I pathway is produced during the pioneer round of mRNA translation. Proc Natl Acad Sci U S A 108, 11572-11577

88. Isken O, Kim YK, Hosoda N, Mayeur GL, Hershey JW and Maquat LE (2008) Upf1 phosphorylation triggers translational repression during nonsense-mediated mRNA decay. Cell 133, 314-327

89. Sharma A, Yilmaz A, Marsh K, Cochrane A and BorisLawrie K (2012) Thriving under Stress: Selective Translation of HIV-1 Structural Protein mRNA during Vpr-Mediated Impairment of elF4E Translation Activity. PLoS Pathog 8, e1002612 